improvement was noticed after the fifth injection and this improvement continued until the fourteenth, when somewhat suddenly new lesions began to appear on all parts of the body. After the seventeenth injection the eruption again began to show signs of improvement, the new lesions, as well as the old, growing paler, but the patient leaving the hospital the treatment could no longer be continued. Two weeks later the patient returned to the hospital, and it was then noticed that the eruption had disappeared completely from the hands and arms and was much improved on the rest of the bodv. In a voung woman, 18 vears old, the eruption had practically disappeared after twenty-six injections. The greatest number of injections given any one case was twenty-seven, the treatment extending over a period of two months. In this case there was also almost complete disappearance of the eruption.

It will be observed from the foregoing summary that while every one of the eight cases responded favorably in some degree, in only two was there anything like an approach to a complete disappearance of the disease. This is not a very brilliant showing, especially when compared with the results reported by Schild and others, but it should be remembered that in my cases the atoxyl was given alone, while in the eases treated by Schild the usual external remedies were employed conjointly with the atxoyl injections and a part of the cure at least is fairly attributable to the local treatment.

In addition to these cases of psoriasis I have recently had an opportunity to try atoxyl in a severe case of pemphigus, occurring in a man, 68 years old. Before coming under my care this patient had been given considerable quantities of Fowler's solution, without controlling the eruption, until severe abdominal pain and diarrhea compelled its suspension. At first a daily injection of 30 minims of a 10 per cent. solution was given, and this was continued for about one week. At the end of this period there was a marked improvement in the patient's condition; new lesions had ceased to appear and the old ones were drying up. The atoxyl was now stopped through some misunderstanding and there was shortly a new outbreak of blebs on all parts of the body. The injections were then resumed, this time two of 30 minims each were given daily at intervals of twelve hours, and at the end of one week the disease again seemed to be under control. At the present time the patient's condition is better than any time since the beginning of the disease. Notwithstanding the large quantity of the drug taken, the only toxic symptom noticed was marked tremor of the arms and legs, which came on after 6 grains a day had been taken for six days; but this promptly disappeared with the temporary suspension of the treatment:

From my experience, limited though it is, I am led to conclude that atoxyl, like sodium cacodylate, does not possess any therapeutic properties not to be found in arsenious acid, Fowler's solution or the arseniate of soda. Owing to its great solubility in water and freedom from irritant properties, it is, however, especially adapted to hypodermatic use, a method of using arsenic often preferable to administration by the mouth and one which usually gives superior therapeutic results.

In conclusion, I desire to say a word or two about an untoward effect of arsenic which deserves the serious consideration of every one who essays to use this potent drug in chronic diseases. It is now well establisher that the long continued use of arsenic, especially in consider- able doses, may be followed by circumscribed keratoses on various parts of the body and more particularly on the palms and soles; and Mr. Jonathan Hutchinson some years ago called attention to the fact that epithelioma may develop at the site of these keratoses, an observation which has since been confirmed by a number of other observers, so that there are now at least twenty cases of such arsenical epithelioma to be found in literature.

\section{WORK CERE.*}

\section{ADDISON S. THAYER, M.D.} PORTLAND, ME.

Before we began the study of psychology and of socalled mental philosophy, many of us over-rated the value of that kind of knowledge. The science of mind, the study of wisdom-these surely should have power to teach a man how to think and how to live.

If we were disappointed--those of us who looked for practical guidaree in the psychologic and philosophic teachings of twenty years ago or of forty years agowe may note to-day in the work of psychologists qualities of promise and of partial attainment-precision, modesty, enthusiasm, practicality. To illustrate, let me quote this one suggestion by William James

We live subject to arrest by degrees of fatigue which we have come only by habit to obey. Most of us may learn to push the barrier further off, and to live in perfect comfort on much higher levels of power.

Scientific psychology is receiving a self-conscious increment, although a small one, from pseudoscientists, from men of one idea, from quacks, who successfully apply, by methods which are repulsive and ignorant and unsound, the soundest of scientific principles; and psychology is seeing and admitting its indebtedness to quackery.

The millions of dollars which have gone to build temples to the honor of Mrs. Eddy, and the millions in medical fees paid to Christian Science healers, constitute a costly demonstration of one permanent scientific fact-that mind-cure is practically useful. Whoever pays the price, this knowledge is ours.

Keenly aware as we are of the value of the psychotherapeutic principles which Mrs. Eddy and her followers have hit on, our estimate of the absurdities of the cult still lacks the proper perspective. Denial of the existence of pain continues to have for us a semblance of reprehensible error, while the average layman sees in such an idea a huge opportunity for good natured ridicule.

'The man in the street is also relatively more ready than we are to take the next step in advance in psychotherapeutics. He is vastly entertained by the mental picture of a Christian Scientist cheerfully oblivious of toothache, but he also soberly assents to the psychologic proposition that any man who has a toothache suffera less if he keeps busy. When our typical therapentic juryman hears evidence that the Earl of Dunmore spent seven months in close communion with bubonic plague, and escaped infection by practicing the precepts of Mrs. Eddy, the evidence is accepted for only a little more than it is really worth. But when testimony is adduced to the efiect that one of the ablest men of our time, finding

* Read in the Section on Pharmacology and Therapeutics of the American Medical Association, at the Fifty-ninth Annual Session, held at Chicago, June. 1908. 
himself on the verge of a nervous breakdown, puts himself in the care of an ex-prizefighter, whose method of treatment is believed to depend mainly on strenuous muscular exercise, the resulting restoration to health is accepted by our juryman as fact, and the method of restoration appeals to him as eminently sensible.

The psychotherapy which nows holds the interest of some of the brightest men in our profession, defined and clarified by the teaching of Professor Dubois, is often lacking in the practical application of this sound, saving, commonplace psychologic law: Nature abhors a mental vacuum. You can't drive out morbid thoughts and keep them out, unless you fill their places with thoughts that are more healthy.

In the treatment of hysteria, as in pedagogy, suggest that an idea is erroneous and you sometimes rivet that idea all the more firmly in the mind. Worry is an endless chain. Tell a man not to worry, and he worries for fear he may worry. He is afraid that he has decided wrongly, but is doubtful whether the opposite decision would be really right.

Our therapeutic purpose is seldom accomplished by telling a patient not to be afraid. To clear the tracks, however, we may rouse his sporting instinct; ask him what is the worst thing that could happen if he decided wrongly and stuck to the wrong decision; then sidetrack his morbid thoughts by giving him no time for introspection; awaken objective interests; make him play the part of a cheerful, active man; and because he is active, he will presently become cheerful.

For therapeutic substitution, Dr. Joseph Collins ${ }^{1}$ suggests a study of Plato's philosophy. Dr. Herbert Hall ${ }^{2}$ recommends the use of the hand loom to call out creative activity in mind and muscle. Whether the instrument be a potter's wheel or a pair of field-glasses pointed at a bobolink, a golf. stick or a garden rake, a wood carver's tool, a fishing rod or a camera, is of minor consequence, if the neurones behind the nerves are aiming out and not in. The best work is play, the best play is work, and both are gaining recognition as means of cure.

Sometimes, for some people to spend three hours at the theater is hard labor. A vigorous opponent at tennis may be a severe taskmaster. One's guide in the woods may rebel at the work which his employer regards as merely strenuous sport. For therapeutic diversion, at least a part of the day's régime will naturally include, if possible, some form of neuromuscular activity, preferably in the open air.

The invention of the medicine ball was probably not the earliest conscious effort to use the curse of Adam as a means of cure; but even now the literature of the subject is relatively meager. Among the first to discuss the value of occupation as a means of therapy were the superintendents of asylums for the insane. As is natural, where the need is greatest, the means of supplying the need have been most fully appreciated; and it has been in the treatment of the insane, and of epileptics, and in the education of the feebleminded that the systematic use of occupation has hitherto shown most striking results.

Although the primary purpose in providing work for inmates of public asylums was to reduce the cost of support through getting done by patients rather than by paid helpers certain parts of the labor of the farm,

1. Am. Jour. Med. Sci., February. 1908

2. Boston Med. and Surg. Jour., Jan. 12 and July 13 ,1905. the laundry and the various repair shops, every observer of the results of this plan has noted also the incidental effect which work has had on the worker.

More than twenty years ago, Dr. G. A. Blumer, ${ }^{3}$ who at that time was superintendent of the State Hospital at Utica, N. Y., published observations of the palliative and occasionally curative effects of manual occupation. Dr. Blumer's faith in work as a means of cure apparently grows with experience. In his report for 1908, as superintendent of the Butler Hospital, Providence, R. I., he says it often happens that "improvement seems to date from the first time the patient entered a shop or workroom."

In the treatment of epilepsy, manual training and the varied interests of colony life have now a value so fully demonstrated, that the example set by the states of New York and Massachusetts, at Sonyea and at Palmer, is creating similar institutions in other progressive states.

So, too, in the education and management of the feebleminded, systematic manual labor has won for itself a place of unquestioned importance.

Idiots and epileptics and lunatics are many; but all together they are less numerous than the victims of nervousness-the people afflicted with lesser grades of psychasthenic and neurasthenic inadequacy, who become devoted epicures of their own emotions, and who claim a large share of the attention of every general practitioner and of every specialist.

The psychoanalytic methods of Freud and Jung, even when employed with subtlety and success for tracing a morbid habit of thought back to the emotional trauma in which it began, constitute only a preliminary procedure, to be followed by measures which are synthetic and restorative. Moreover; psychoanalysis is sometimes dangerously suggestive.

At the Adams Nervine Asylum, Jamaica Plain, an endowed institution, the privileges of which are restricted to residents of Massachusetts, and to patients who are not insane, a workroom has been in operation for two years. "It has furnished a department in which the atmosphere of illness is distinctly lacking and where a spirit of interest in tangible and practical occupations is present. Discussion of symptoms is entirely forbidden. It has convinced patients that they can do things worth while, although they have long been possessed of the contrary notion." The resident physician, Dr. D. H. Fuller, finds this form of treatment increasingly useful.

At Katonah, forty miles from New York City, Dr. E. A. Sharp is using the farm and the workshop, the toboggan shute and the saddle, as means of cure.

I) uring the past nine years, Dr. Philip King Brown, of San Francisco, has made use of occupation as a means of therapy, in private practice, and also at his sanitarium in Santa Barbara. Dr. Brown has used basketry, sloyd and carpentry, the carving and stamping of leather, botany, gardening, ornithology, geology and even astronomy-"any uccupation which will train the patient's mind to run naturally in a different channel. It is not so much the work," he says, "as the way you inspire the person to take it up. The psychic influence is without question the largest part. That form of work is best which interests the patient and leads him on to more and more thought of things outside himself."

These principles, which include a wise and salutary neglect of subjective symptoms, have been practically ap-

3. Am. Jour, of Insanity, 1897, vol. liv, No. 2. 
plied at Bethel, Maine, by Dr. John Gehring, and at Heath, Mass., by Dr. Grace Wolcott, of Boston.

A majority of the physicians who have given attention to this subject, regard the material article, produced as a result of labor, as being in itself relatively unimportant. This is not the belief of Ir. H. J. Hall, of Marblehead, Mass., who disapproves of the kind of work which represents conscientious activity and nothing more, and who insists on work which has inherent value. In his shop of arts and crafts, Dr. Hall encourages his patients to produce pottery, rugs, and various articles in metal and wood which shall evince a genuine artistic merit. The proceeds of the sale of these articles is credited to the patient. Dr. Hall takes brokendown school teachers and makes of them successful artisans.

Clay modeling and basket weaving are now used therapeutically in the out-patient service of the Massachusetts General Hospital. Dr. Charles E. Atwood, ${ }^{4}$ of New York, and Dr. Robert N. Willson, ${ }^{5}$ of Philadelphia, have recently described various methods of utilizing, in practice, certain forms of diversion and of exercise.

It is a fair criticism of the beneficent modern treat ment of tuberculosis-rest, forced feeding and fresh air-that some of its graduates are all too well content with their life of fed and fatted monotony. In a sanatorium for consumptives at Frimley, thirty miles west from Iondon, the rest cure is supplemented by the work cure. Fxercise is carefully graded from a short walk to a long excursion behind a lawnmower. Promotion is regulated by subsidence of fever, of certain subjective sensations, and of elange in opsonic index. When conditions favor, the patient turns loose into his system a fresh dose of bacterial vaccines by more work. A diploma from Frimley is a practical asset.

Colony sanatoria for neurasthenics have not yet come into being in this country. In Germany, at Schönow, Rasemühle and 7ïrich, ${ }^{6}$ beginnings have been made; and here earpentry, gardening, bookbinding and similar occupations hold high places in the prescribed régime.

The psychotherapy of Dubois and of Dejerine usually begins with a period of rest. Rest periods and diversity of employment are essential features in the programs which we construct. The experimenting physiologist tells us that a frog's nerve will respond to one irritant until exhaustion comes, and then, for a time, will respond to a different stimulus. Work, change and rest, which naturally succeed each other, sometimes successfully replace each other.

When we come into subconscious possession of the idea that occupation is frequently the finishing touch in therapeutic procedure, we utilize, perhaps unconsciously, an effective aggregate of apparently trivial means. In treating most of our patients, the end toward which we therapeutically struggle is heightened power of resistance to disease. For the development of antibodies is there any single agent more effective than work?

\section{ABSTRACT OF DISCUSSION.}

Dr. F. X. Dercum, Philadelphia: We neglect the matter of occupation too much. We should bear in mind the necessity of applying just such simple physiologic methods as have been advocated by Dr. Thayer. We are confronted by the three great neuroses, neurasthenia, hysteria and hypochondria.

4. The Favorable Influence of Occupation. New York Med. Jour., Dec. 14.1907 .

5. The Pathogenesis and Treatment of Neurasthenia. Am. Jour. Med. Sci., February, 1908.

6. A Colony Sanatorium for the Neryous and Neurasthenic. Genrge W. Jacoby, M.D., New York Med. Jour., April 19, 1908.
We can not put every neurasthenic at work because his nervous battery, so to speak, has been too much exhausted; but we should not neglect after a period of rest to start him at work. If the patient is not put back in the channel in which he is aecustomed to expend his energy, or started in some new occupation, sooner or later recurrence may ensue. In case of hysteria, if there be no marked involvement of general health, the rest eure is often unnecessary. Only the direction of the energies into the proper channels is required. Of course, if the general health is impaired, rest methods, partial or complete, are imperative; the adoption of such methods should always depend on the judgment of the physician. In hypochondria, work-often strenuous and engrossing work-is the oniy thing that does good. The hypochondriac is simply obsessed by the idea of illness. We can not dismiss such a patient with the statement that he is not ill, because in one sense any departure from the normal state is illness; besides hypochondria is a well-recognized psychoneurosis. The highest degree of health is consonant, other things equal, with the highest degree of functional activity; functional activity of a high order is not only conducive to health, but also to longev ity. All of the world's great men have been workers and almost all have attained great age.

One of the difficulties, of course, is to find an appropriate occupation for a given case. Sometimes I have a patient taught stenography and typewriting or $I$ have her take a course in library work; I endeavor to find something that I hope will interest her. I know nothing more difficult than to select the proper kind of work. If the patient happens to be in the fortunate position of being obliged to earn a living, the problem is easier. Of course, the work cure is an instrument that is also capable of doing harm. We differ largely in regard to the amount of labor we are capable of performing without ill effect. It is necessary to use individual judgment in apportioning work and rest properly. In the great majority of cases work of some sort is of inestimable value, for it necessitates, among other things an objective, instead of an introspective attitude of mind.

Dr. Alexander S. von Mansfelde, Ashland, Neb.: The best proof of the pudding is the eating. In 1874, the founder of the College of Physicians and Surgeons of Chicago came to me, a young man in the profession, and asked me to translate for him a monograph on histology. I was so proud of the distinction that $I$ overdid the work mentally and physically I collapsed. My physician caused me to leave my work at 4 in the afternoon and engage in what was then a new game, croquet. At first they could not get me out very easily; a little later, when 4 o'clock came I could not do anything in the work of translating. I am still here, and it must have done me good. Are not many physicians in the same condition as some patients outside of the profession? Is it not true that both need a vocation and an avocation in life-that avocation is the thing that overcomes many of our ills? My avocation has been the cultivation of flowers. I try to raise flowers that nobody else has ever raised. I use the hoe and spade, and the result is, I recuperate in my avocation after the intense work of the winter in my vocation. Winters in Nebraska are trying, and for twenty to thirty years I have traveled twenty to forty miles and more a day. This and the strain of trying to make the dollars, which were few enough, go as far as possible for thirty years, make it easy to go down hill. The avocation during the summer invariably restored me after the hard winter. So I am a living witness of the truthfulness of Dr. Thayer's statements.

Dr. Adpison S. Thayer, Portland, Maine: The chief object of the paper was to call attention to work cure in everyday practice. Each of us can use it in constructing a daily régime for our patients. I first put together as a part of the paper a brief account of the application of the work cure as I had seen it in people whom I know, most of whom I had treated; but it is easy to see that such accounts do not lend themselves as case reports to a paper for publication. Dr. Dercum has said that hypochondria work cure is the only treatment. That is another way of stating that occupation has a wide range of therapeutic usefulness; for we know that many of our patients have in their symptoms some element of hypochondria. 